\title{
PREPARATORY STAGES OF CLISIOCAMPA EROSA STRETCH.
}

\author{
BY HARRISON G. DYAR, BOSTON, MASS.
}

CLISIOCAMPA EROSA Stretch.

I881. - Stretch, Papilio, i, 67.

Egg. - The eyg mass is small, laid to form a ring near the tip of a twig, and covered with varnish. Its length is about ${ }_{5} \mathrm{~mm}$., the thickness only slightly greater than the longest dimension of the eggs. The eggs are irregularly cylindrical, flattened above and below, and closely packed. Color white, but smeared with the dark brown frothy varnish. Diameter $.5 \mathrm{~mm}$; height $.8 \mathrm{~mm}$.

First larval stage.* - Head rounded, shiny black, whitish at vertex, with short pale hair; width $.40 \mathrm{~mm}$. Body cylindrical, velvety black, except an obscure paler substigmatal line. Long whitish hairs arise from minute black warts, several from each, but with a shiny base to each hair. The larvae spin no nest, but merely a slight web over the leaves upon which they rest. In the later stages they are often found in large masses low down on the trunks of the trees without any covering. They resemble Clisiocampa disstria in habit.

Second stage. - Head higher than wide, rounded, black; width $.65 \mathrm{~mm}$. Cervical shield, warts and thoracic feet black; body blackish, with subdorsal, lateral and substigmatal yellowish white lines; a faint dorsal line of bluish white. Hair long, thick, white, spreading from the small warts. Joint 12 is a trifle enlarged. As the stage advances the body becomes blue gray, except the lateral region which is brown gray; the lines are ocher yellow, the subdorsal one with a broad black band above it, leaving a dorsal band of blue gray. On joints 3, 4 and 12 are large, elevated, velvety black, subdorsal spots, one on each.

Third stage. - Head rounded, black with a slight bluish tinge; width r. I mm. $\dagger$ Body

* I did not find the eggs until they were hatched; but $I$ feel confident that the larvae had not passed a moult. black, joint 2 bluish with a large subdorsal wart; large black spots on joints 3 and 4 . A dorsal blue line, broken into a series of nearly connecting segmentary spots, enlarged on the anterior part of the segment and tapering behind, present only on joints 3-I2. Joint I3 bluish. An orange subdorsal line; a blue band below it; a yellowish lateral line; a narrower blue band; a substigmatal yellowish line, each of these narrowly separated by the black ground color; a yellowish line along the bases of the legs. Abdominal feet black, testaceous at tip. Venter black.

Fourth stage.-Head bluish with small black spots, labrum white, jaws black; width $\mathrm{r} .4 \mathrm{~mm}$. Body flattened below, feet spreading, joint I2 a little enlarged dorsally. A row of white dorsal spots, one on each segment on joints 3-I I but nearly broken into two, a large spot narrowly connected with a little one behind it. The orange subdorsal line is supplemented by a few orange dashes in the dorsal space; lateral and substigmatal lines orange but paler, the blue filling in nearly the whole space between them, except for the spots on joints 3, 4 and 12, and a row of much smaller ones on the intervening joints. The broken line along the bases of the legs is pale orange. Joints 2, r 2 posteriorly and I 3 are blue gray. Hair all reddish, thin on the back, but quite thick subventrally. Feet black, the abdominal paler at the tips.

Fifth stage. - Very much as before; width of head 2.I $\mathrm{mm}$. The anterior one of the two white dorsal spots on each joint of joints $3^{-12}$ is pointed behind and followed by the posterior small rounded spot. On joints 3 , 4 and 12 the blue band is broken by a quadrate black spot as in the previous stage and on joints $5^{-1} \mathrm{I}$ and $\mathrm{I}_{3}$, there is a small black spot, defined as an incision in lower edge of band.

$\dagger$ This is abnormally large, but the measurement was made with care from several examples. 
Sixth stage.-Nearly as in the two previous stages; width of head $3.2 \mathrm{~mm}$. The dorsal space is partly filled in with blue, except for a black edging to the dorsal white spots, a black spot on each side of the white spots at their obsolete junction and the short orange red streaks supplementary to the subdorsal orange red line. The white spots on joints 3 and 4 are larger than the others, single, elongate, and in some examples the posterior white dot on all segments is partly orange or rarely obsolete. The blue band is minutely black dotted, followed by the pale orange lateral line which is rather irregular. Space below, blue gray, the substigmatal line and the one along the bases of legs yellowish faint and broken, or obsolete; spiracles large, black; feet gray; venter blue gray with a median row of black spots. The cervical shield and anal plate are blue gray tinged with black. Subdorsal warts on joint 2 rather large; joint I2 enlarged a littie dorsally. Dorsal hair very scant, blackish, the subventral hair thick, partly silky white with some dusky and reddish hairs intermixed.

Cocoon.-Enclosed in an outer layer of silk, elliptical thin, composed entirely of silk, made opaque by an exudation from the anus of the larva, which dries into a pale yellow powder. Size $25 \times 8 \mathrm{~mm}$.

Pupa. - Cylindrical, posterior abdominal segments rapidly tapering, rounded at both ends, no cremaster. Color black, rather shiny, covered with short brown pile, except the cases which are bare. Length $18 \mathrm{~mm}$.; width $4 \mathrm{~mm}$. Duration of this stage 26 days. The moths appear during July.

Food plants. - Oak (Quercus), poplar (Populus), willow (Salix), alder, (Alnus), wild rose, (Rosa), peach and cherry (Prunus), apple (Pyrus) and others.

Habitat.-Oregon and Washington west of the Cascade range. Found at Portland and Bonneville, Oregon, Seattle and Vancouver, Washington. This is the common Clisiocampa of the Pacific Northwest and takes the place of $C$. disstria of the Atlantic States. It is abundant in the valley of the Columbia, but becomes more rare to the north. But two larvae were seen in Seattle, Wash., while in Portland, Or., many fruit and shade trees were largely defoliated by the larvae, and they were frequently observed resting in large compact masses on the tree trunks.

A lower Silurian insect from Sweden. -For a long time the Devonian insects of New Brunswick were the oldest known from any part of the world. Seven years ago, however, Brongniart discovered in the lower part of the upper Silurian of Calvados, France, a single wing which he regarded as a cockroach and named Palaeoblattina douvillei. And now Moberg announces the discovery of an hemipterous insect, which he calls Protocimex siluricus, in the still older rocks of Flagabro in Scania, belonging to the upper members of the lower Graptolitic slates, that is the upper part of the lower Silurian. Figures are given in the Förhandlingar of the Swedish geological society.

Entomological Notes.- The first signature of a new general Catalogue of Hemiptera has just been issued by Lethierry and Severin at Bruxelles. The arrangement is systematic down to the genera but the species are given alphabetically and the number of species added at the end of each genus and subfamily. The present sheet includes a portion of the Pentatomidae: the Plataspidae (I9 genera and 187 species), the Corimelaenidae (Io genera, 66 species) and a few Scutelleridae. It will prove of great service.

Entomologists everywhere will regret to hear that the serious illness which has, for the past two years, incapacitated Dr. H. A. Hagen renders it improbable that he will be able to do any further work. Dr. Hagen has had charge of the collections of insects in the Museum of comparative zoology at Harvard University since October $\mathrm{I} 2, \mathrm{I} 867$, and during this long period of twenty-five years has applied himself with entire devotion to the interests of the department. The scientific 

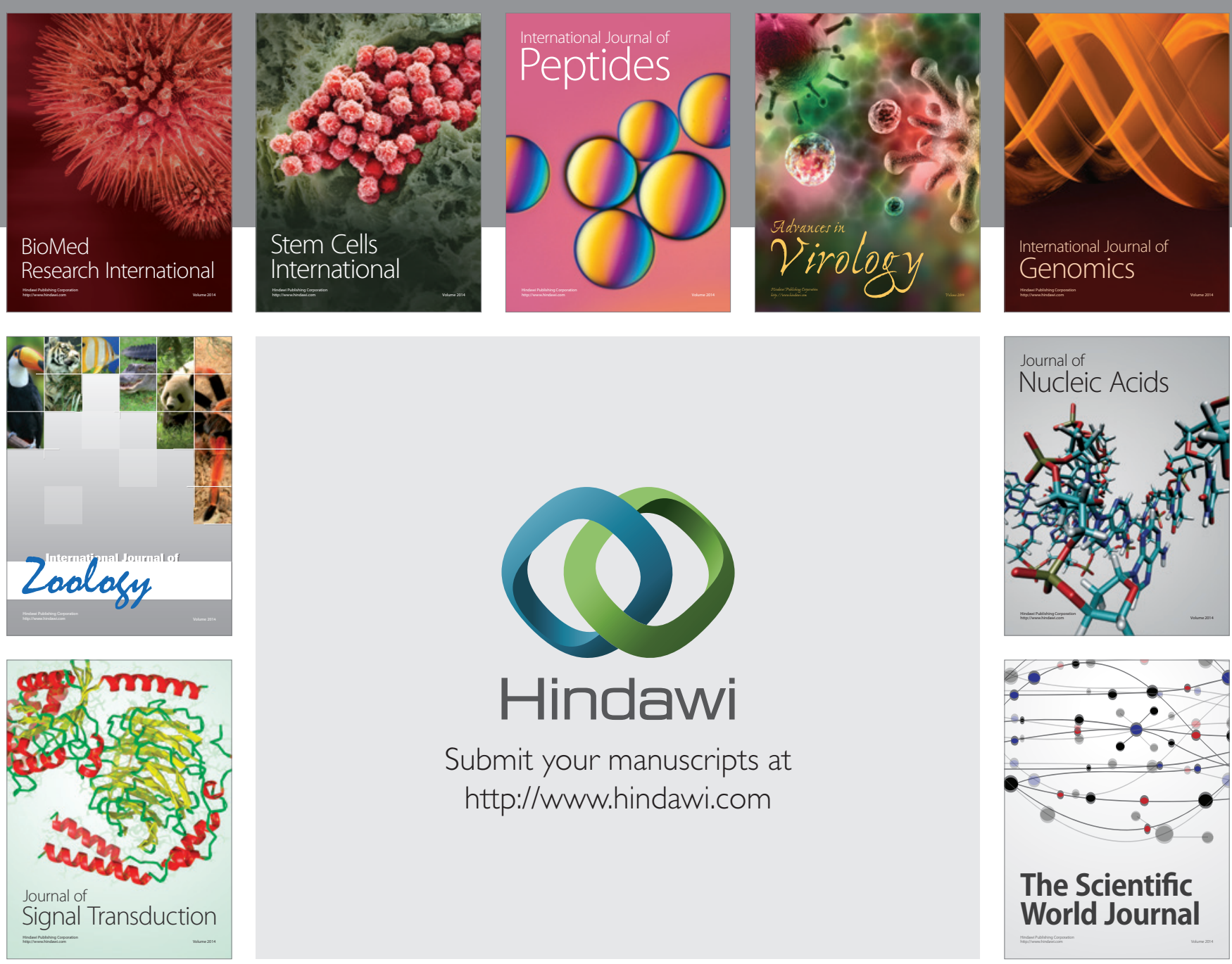

Submit your manuscripts at

http://www.hindawi.com
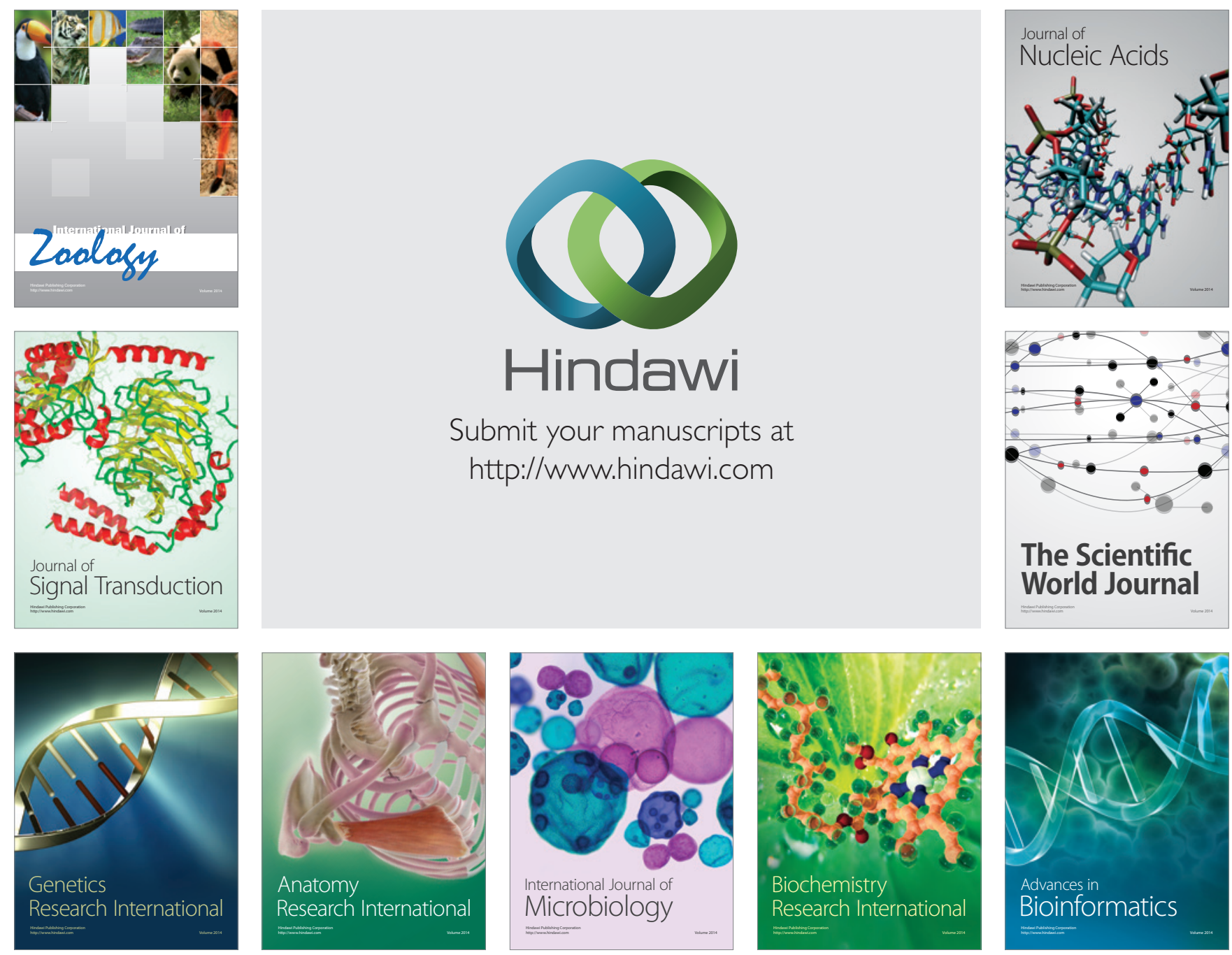

The Scientific World Journal
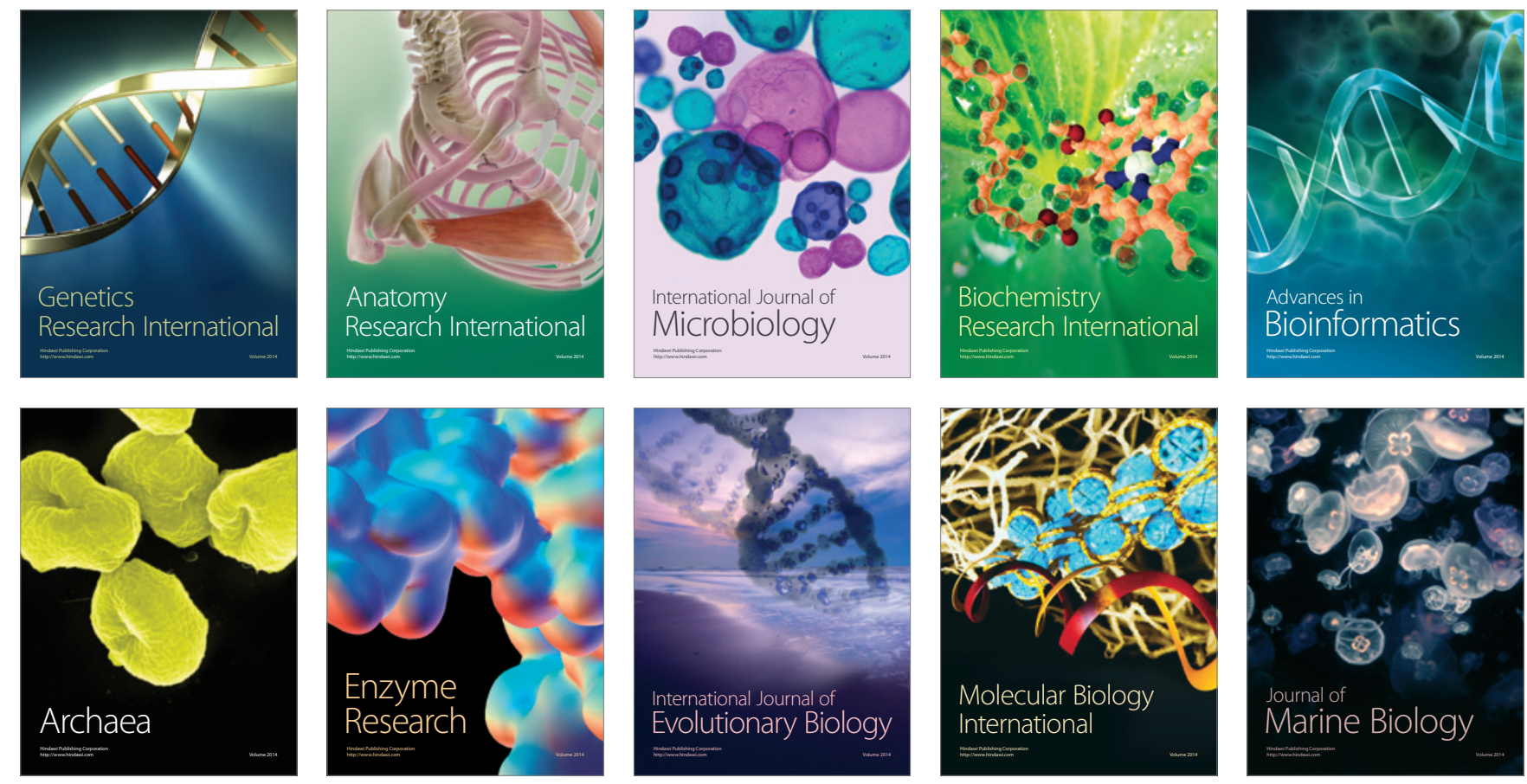